\title{
Empirical Review of food crop technologies Adoption in Ethiopia: Meta-Analysis
}

\author{
Zeksarias Bassa* \\ Department Agricultural Economics, Haramaya University, Ethiopia
}

*Corresponding author: Zekarias Bassa, Department Agricultural Economics, Haramaya University, Ethiopia.

Received Date: May 13, 2019

Published Date: June 11, 2019

\begin{abstract}
Adoption of improved food crop technologies is known to be the prerequisite for productivity improvement. However, due to different socioeconomic, demographic and institutional factors the level of food crop technology adoption and utilization is not optimal. A meta-analysis is performed to review empirical estimates of Adoption factors of improved food crop technologies in Ethiopia. The result indicated the adoption of the technology defined by sample size, technology type, study period. The analysis result also confirmed that the mean size effect of food crop technology adoption estimate is function of training, irrigation, extension service and credit access, oxen holding, cooperative membership, TLU, labor force and income. This implied that through awareness creation, improving farmer to farmer and farmer to extension and research linkage, improving credit access, infrastructural development, livestock ownership and income earning opportunity, it is possible to accelerate the speed of food crop technologies. The study results also justified that food crop technologies only focused on the specific technology type and quantity, not on how the technology implemented by farmers, these assumed to be probable reason for low adoption of improved practices that resulted in low agricultural production and productivity the sector.
\end{abstract}

Keywords: Adoption; Food crop; Means size effect; Meta-analysis; Ordered Logit; Technology

\section{Introduction}

Modern agricultural technology defined and summarized in different major categories such as application of optimum rate of fertilizer, irrigation, intensive tillage, monoculture, use of chemical for pest control, improved soil and water conservation, improved natural resource management agronomic practices, improved value addition, improved livestock rearing and feeding, improved harvesting and post-harvest handling practices Abdul et al. [1].

As sited by Paul [2] farm technology referred transformation of producers from using unproductive and endangered seed to productive variety, enabling farmers to reflect their role in demonstration and invent that enhances technology dissemination and shorten unnecessary resource wastage in the process. Thus, despite its prehistoric origins and hayseed caricature, farming is the source of Invention of all technology.

The study results confirmed that large efforts were made to increase agricultural productivity through technology dissemination in Ethiopia, but food insecurity remains a major challenge in the country. Improving smallholder's productivity demands sustainable adoption of suitable and package-full agricultural technologies and practices. It also reported that the socio-economic factors plays detrimental role in agricultural technology transfer and dissemination; but little attention given for the role of social capital in technology adoption and its potential to create collective actions, reduce transaction costs, relax supply side constraints, and disseminate information Nizam et al. [3].

The study results revealed that the benefit of agricultural technology realized in enhancing production and productivity can be justified when yield increasing technologies are widely been demonstrated, disseminated and used. The agricultural technology adoption decision of farm households has been found to be function of irrigation use, land ownership right, security, credit access, distance to the nearest market, plot distance from the home stead, off-farm participation and tropical livestock unit Berihun et al. [4].The other result also implied that farmers who adopt technologies once are more likely to adopt the technologies due to its the profitability of agricultural technology adoption and agricultural extension services and technology adoption have a 
statistically significant and positive impact on nutrition and food security Tigabu and Gebeyehu [5].

Agricultural technologydevelopmentandadoptionisanessential approach for increasing agricultural productivity, achieving food self-sufficiency and alleviating poverty and food in-security among smallholder farmers in Ethiopia. In Ethiopia, farmers have been adopting and using different agricultural technologies at different proportion in relation to difference in Socioeconomic, institutional and environmental factors; the adoption of technologies has not completely optimal yet. Therefore, it is needed to further promote agricultural new technologies by designing based on farmer's problem and demand. The article reviewed on the issue revealed that major explanatory variables significantly affect the adoption of agricultural new technologies by farmers comprised of age, education level, training and demonstration access, family size, tropical livestock unit, market distance, gender, farm size, improved infrastructure access, extension service provision and credit access Melesse, Leggesse et al. [6,7].

Empirical studies result on adoption of agricultural technologies in Ethiopia were concentrating on the adoption of fertilizer and improved seed varieties. However, the adoption rate of technologies by farm household is complex and interlinked that based on the type of technology and the time of study, lagged variables, socioeconomic and institutional factors. The farm households were adopting more of chemical fertilizers than improved seeds and their adoption rate increases for more recent studies Aynalem et el. [8].

The study result shows that younger farmers, famers with larger land size, farmer living closer to market, and farmers who had closer contact with the extension system are more likely to adopt new technology in better manner and proportion and use it more. The result underscores the need for research and extension programs to be sensitive to the needs of farmers when developing and disseminating technologies that are relevant to their agroecologies Admassie and Gezahegn [9].

The study results by Solomon et al. [10] show that knowledge of existing varieties, perception about the attributes of improved varieties; household wealth (livestock and land) and availability of active labour force are major determinants for adoption of improved technologies. The finding also suggests that the adoption of improved agricultural technologies has a significant positive impact on farmers integration into output market and the findings are consistent across the three models suggesting the robustness of the results Chilot et al. [11].

Doss et al. [12] found that extension was the variable most significantly affecting with wheat and maize technology adoption, and extension services continue to play an important role in disseminating information on new varieties and how to manage them.

Yohannes et al. [13] reported that economic factors such as income, wealth and debt family size, access to outside information, education and experience significantly known to influence on the adoption of pesticide technologies. The effect of socio-economic factors on adoption of fertilizer and pesticide technologies is greater in the area which has more access to outside information and offfarm activities than in more 'self-contained' area. The impact of the degree of risk aversion of farmers is found to be significant for fertilizer and pesticide technologies in only one area.

In General, the transfer and utilization of improved agricultural technologies depends on social, economic, environmental, institutional and demographic factors that all known to impose detrimental role in the system. However, the attention given to listed factors are uneven and related to these the speed of technology transfer and utilization was at stagnant position. In addition to these the agricultural constraints not listed in the way to generate information and policy formulation. Hence, the Meta analyses study in food crop technology at country level aimed for generation information over the technology adoption factors and the mean size effect of socioeconomic, institutional and demographic factors over adoption rate of food technologies.

\section{Methodology for Meta-Analysis of Food Crop Technology Adoption}

The methodology employed critical reviewed that supported by Meta-analysis of food crop technologies in Ethiopia. The major reviewed articles were the one that carried out in potential food crop production regions of Ethiopia such as Oromiya, SNNPR, Amhara and Tigray. The articles reviewed comprised that done from 1990 up to 2018.In the Meta-analysis, about 150 significantly influencing independent variables used that gathered from 48 different articles published and summarized to 48 observations from the Google. The articles reviewed categorized as cereal crop, pulse crop and root and tuber crops. The technologies defined for adoption food crop summarized consists of improved varieties, artificial fertilizer, chemicals for pest control and sowing method. The major food crops from which reviewed information gathered include wheat, maize, Teff and barley, from cereals, soybean, common bean and fababean from pulse crops, potato from tuber and root crops. From reviewed articles data created on excel and organized to see the mean size effect of commonly affecting variables over adoption of food crop technologies. The major data synthesized from reviewed articles include model type, publication date, year with author, data type, region the study done and sample size. The mean size effect independent variables selected based on its level of appearance at different articles. The explanatory variables gathered and synthesized for analysis comprised of gender, family size, age, education level, market distance and access, cooperative membership and distance, livestock ownership, TLU and oxen holding, training, participation in field day, market access for input and output market, market distance, land size and plot distance from homestead, price perception, risk and nutrient perception, road access and distance, artificial fertilizer used, irrigation access, seed availability, fertility, extension access and contacts, income, machinery rent, fertility, district and radio ownership. 


\section{Steps followed in analyzing data in Meta-Analysis for food crop technology adoption}

- $\quad$ Calculating Standard Error (SE)

All Standard errors estimates derived from the formula se= $\frac{\sum\left(X^{-}-\mu\right)}{\sqrt{n}}$ and it was already estimated by reviewed article in statistical software and it directly copied from the papers. The Standard errors are can be also simplified derived equations for different types of studies. Since we are using rates, we can use $S E=\frac{e s}{\sqrt{n e s *} n}$, where es is size effect and n number of subjects.

- $\quad$ Computing variance (Var)

This formula is simple: $\operatorname{Var}=\mathrm{SE}^{2}$. In Excel it was calculated by just squaring the estimated standard error, Var=squarer of Standard errors.

\section{- $\quad$ Computing individual study weights (w)}

The weight estimated have to to be estimated that weight each study with the inverse of its by dividing 1 by its variance, so the weight variance calculated as $\mathrm{Wi}=\frac{1}{\sqrt{\operatorname{Var}}}=\frac{1}{\sqrt{s e 2}}$

- $\quad$ Computing each weighted effect size $\left(\mathbf{w}^{*} \mathbf{e s}\right)$

This is computed multiplying each effect size that equals to coefficients by the study weight. Therefore $\boldsymbol{W i Y i}=\boldsymbol{W i} \boldsymbol{i}^{*} \boldsymbol{Y}$, where $\boldsymbol{W i}$ is the weighted effect size and Yi the value of coefficients over study results.

\section{- $\quad$ Other necessary variables ( $\boldsymbol{w}^{*} \boldsymbol{e s} \mathbf{2}$ and $\mathbf{w} \mathbf{2}$ and $\boldsymbol{M}^{*}$ )}

These two important variables estimated by just multiplying the calculated results. This is to mean that $w^{*} e s$ and w2. From these values the Mean size effect calculated by the formula $M^{*}=\frac{\sum Y W}{\sum W}$ where $y$ is the value of coefficients and $w$ is the weight.

- Calculating Variance, Standard Error and t value

The variance can be calculated by $\operatorname{Var}=\frac{1}{\sum W}$ and from this SE

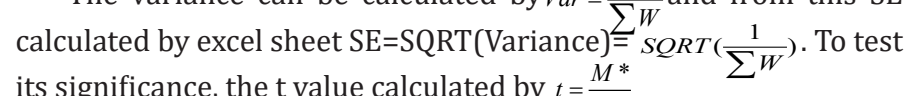

- $\quad$ Empirical model

The empirical model of the meta-analysis regressed using Multinomial logit model procedure. The empirical model considered adoption rate of food crop technology as dependant variable and study region, model type used, data type, food crop technology type used, study period, sample size as explanatory variables. The adoption probability estimate of the specific technology defined as function of sample size, model used, data type, year of publications and region where the survey done, The mathematical expressions of defining the adoption rate function can be written as: $Y=f\left(n, x_{1}, x_{2}, x_{3}, x_{4}\right)$

Where $\mathrm{n}$ is the sample size for the specific study, $\mathrm{x} 1$ is the model type (defined as 1 if Probit and 0 otherwise, $x 2$ is data type used (defined as 1 if cross sectional and 0 otherwise) , $x 3$ is the year of the publications (labelled as 1 if the study undertaken after 2010 and 0 otherwise), $\mathrm{x} 4$ referred to the region where the study done (labelled as 1 if Oromiya and 0 otherwise).

\section{Critical article Review and synthesizing on food crop technology adoption}

Review in technology adoption of cereal crops in Ethiopia: The study report by revealed that when the farmers access fertilizer and seed their access to extension services seemed automatic and that production specialization together with wealth play a major role in explaining crop area under fertilizer and improved seed for cereal crop production Bingxin et.al. [14]. Extension service, risk aversion behaviour, wealth and land fragmentation played detrimental role in adoption of fertilizer in cereal crop production Bingxin and Alejandrot [15].

Practical training has positive and significant effects on the likelihood of adopting improved varieties of barley; secondary level education has positive and significant effects on the likelihood of adopting improved varieties of barley and wheat. Hence, efforts to increase adoption of improved barley and wheat varieties would more likely be successful if accompanied with practical trainings and demonstrations Chilot et al. [16].

Medkissa et al. [17] indicated that for the strength of wheat production system, the existences of strong farmers-extensionresearch linkage among actors within the system has a vital importance in a way that to transfer skill, knowledge and provision of improved bread wheat varieties in efficient and effective manner is mandatory.

The empirical study result by Tesfaye et al. [18] showed that the existence of supportive relationship between household head sex, field day participation, roads access, and district potentiality in enhancing the adoption of improved wheat varieties. The level of improved wheat varieties was also known to be inverse function of household head gender and road access to all weather roads. The level adoption of improved wheat varieties is defined as function of access to credit, active family force, market distance and district potentiality. The overall findings of the study emphasized household head sex, field day participation, access to all weather roads, access to credit, active family force, district and market distance as being key determinants on the intensity and adoption of use of improved wheat varieties.

The farmer's total wheat area, number of livestock, and the use of hired labour and credit significantly influenced the amount of fertilizer used. The age of the farmer, the use of credit, and several varietal characteristics preferred by farmers (disease and lodging resistance and baking quality) significantly influenced the area allocated to improved wheat varieties Bekele et al. [19].

The use of local and low-yielding wheat varieties, incidence of diseases and pests, poor agronomic practices and declining soil fertility have been identified as major constraints to low wheat production and productivity in Ethiopia. Household level human capital, household asset endowment, farm level institutional factors and policy variables significantly affect the raw planting technology adoption of Teff production in Southern Ethiopia Geremew et al. [20]. 
The study report revealed that household being headed education level, family size, Farm size, annual off-farm income, distance to nearest market and training on row planting significantly influenced adoption and level of adoption of row planting. Moreover, adoption of row planting is significantly affected by Farming experience, No. of information sources and distance to Farmers training centres whereas level of adoption of row planting by livestock (TLU) and Number of oxen Tafesse [21]. Joachim et al. [22] found that row planting for Teff yields higher productivity at demonstration than at large scale area of production due to implementation problem in recombined agronomic practices.

The survey result revealed that farm size, household income, access to credit, contact with extension agents, participation in training, and field day were positively and significantly influenced whereas, age of household and market distance negatively influenced adoption and intensity of use of improved highland maize varieties production in the study area Dawit and Abduselam [23].The study result revealed that difference in production district, labour force, membership to cooperatives, distance to FTC, and livestock holding significantly affected smallholders' intensity of adoption of DAP in maize production Ketema and Kebede [24].

The survey result in eastern Ethiopia indicated that there are positive relationships between improved seed and fertiliser and between improved seed and soil conservation. There were also negative relationships between adoption of manure and fertiliser and between manure and improved seed. The estimation results indicated that the variables affecting farmers' decisions to adopt a technology differ between technologies. Educational level of the household, family size, off /non activities, livestock ownership, and distance to the market, plot ownership, slop of the plot and other variables also play significant roles, partly with differing signs across technologies Musa [25].

The study result by Bedru and Dagne [26] indicated that Adoption of hybrid maize varieties depends on ages, education level, farm size and land proportion allocated to specific crop, extension service, market distance and altitude of the district. Bedru et al. [27] expressed that farmland size positively influences the adoption of improved OPVs of maize. On the other hand, the adoption decision of improved OPVs is negatively influenced by distance from the nearest grain market. The frequency of substantial yield stress encountered due to drought is an impediment to adoption of improved OPVs of maize and is of concern for mitigation through adoption of improved drought tolerant maize varieties. Abadi et al. [28] confirmed that adoption of the improved maize varieties among Maize producer households was found to be positively influenced by adult-literacy, family size, livestock wealth, access to output market and credit access for the new varieties. On the other hand, farmer associations, distance to main markets and fertilizer credit negatively influenced adoption.

Ketema and Kebede [29] indicated by study result revealed that variation in districts, family size, membership to cooperatives, distance to farmers training centre, and livestock holding significantly affected smallholders' intensity of adoption of DAP in maize production. On the other side, variation in district, farming experience, farm size, membership to cooperatives, dependency ratio, and annual income significantly determined intensity of adoption of Urea. Tesfaye and Alemu [30] found that level of education and family size were found to significantly and positively influence die adoption decision of improved maize and chemical fertilizer. Different maize varieties have different productivity at due to different in potentiality across districts Musba [31].

Factors affecting the adoption rate and intensity and utilization of the improved sorghum varieties across their suitable agro ecology summarized as extension service, access to improved varieties and its production packages, training in form of awareness creation and field day and access to market points for farmers Kinfe [32].

Review of Root and tuber crop technology adoption: Although potato is one of the strategic crops for ensuring food security in Ethiopia, the adoption of high yielding and disease tolerant improved potato varieties is low. Higher education of the household head and the presence of a radio and/or television also have a positive effect on adoption. As to the scale of adoption, we found that only the percentage of owned land, tuber size (of ware potatoes), access to credit, stew quality, and presence of a mobile phone have an impact on ware potato farmers' decision on the amount of land to be used for growing Improved Varieties Gumataw et al. [33].

Ketema et al. [34] confirmed that Variation in districts, access to irrigation, farm size, membership to cooperatives, and annual income of the households were found to significantly affect the adoption of potato technology package. Kebede and Ketema [34] study result revealed that variation in districts, access to irrigation, frequency of extension contact, and livestock holding significantly affected intensity of adoption of both DAP and Urea in potato production.

\section{Review on adoption of pulse crops}

The study by Alemneh et al. [35] showed that the household head educational status, age, land size and household size affect consumption and production of pulse crops. The survey result by Chilot et al. pointed out that practical training has positive and significant effects on the likelihood of adopting improved varieties of fababean. Hence, efforts to increase adoption of improved agronomic practices and varieties would more likely be successful if accompanied with practical trainings and access to improved knowledge.

Hagoes et al. [36] study result revealed that the decision to adopt improved fababean varieties is positively influenced by annual farm income and training obtained but negatively influenced by residents of the household heads. The study concludes that adoption decision was found to be a combination of economic, physical and institutional variables of the farmers.

The survey results show that knowledge of existing varieties, perception about the attributes of improved varieties, livestock and 
land ownership and availability of active family labour force play a significant role in enhancing the level of adoption of improved chickpea varieties. The report also confirmed that adoption of improved agricultural technologies has a significant positive impact on marketed surplus and the findings are consistence across the three models suggesting the robustness of the results. Integration into output market is also positively associated with household wealth and availability of active family labour force and negatively associated with age of household head and distance to main market Solomon et al. [37].

The decision to adopt white haricot beans variety is known to positively supported by frequency of extension visits, land size allocated to haricot beans, agricultural income, price perception, training obtained and perception on fertility enhancement benefit of the crop, and negatively by distant to market, ownership of haricot beans farm land (ten and nutritional perception of the crop. The intensity of adoption of white beans is affected negatively by the number of dependents in the household, ownership of haricot beans land (tenure) and positively by non-farm income and contact with non-governmental organizations Daniel et al. [38].

The survey result by Yitayal and Adam [39] revealed that that speed of adoption of beans better at male headed households compared to female headed households and the size of cultivated land, proximity to extension office and remoteness to fertilizer market hastened adoption, while dependency ration and livestock ownership contributed to accelerated in the adoption probability.

The study result of various findings indicated that household head's attitude towards common bean production technology package, participation in extension event (participation in training and field visit) and access to credit were important variables which had positively and significantly influenced adoption and intensity of adoption of improved common bean production package. Whereas, perceived relative is advantage of technology attributes of the household head had shown negative relationship with adoption and intensity of adoption. Some farmers who previously adopted improved common bean varieties have discontinued planting the varieties mainly due to market problem and poor management practice Amanuel and Girma [40].

The study report indicated that existence of the variation in adoption of improved varieties that implies difference in access to inputs and information about the improved varieties. At present input supply (especially seed) is limited or non-existent particularly in the remote chickpea producing areas EARO [41]. The study result by Samuel et al. [42] showed that attendance on training of soybean production and use of soy food at home affects soybean adoption positively and significantly. However, age of the household head and distance to main market has negative and significant impact.

\section{Review on adoption of artificial fertilizer}

The survey results indicated existence of positive impact of extension and credit services, age, farmland size, education, livestock, off/non-farm income and gender in enhancing the adoption of inorganic fertilizer. Physical characteristics like distance from farmers' home to markets, roads, credit and input supply played a critical role in the adoption of inorganic fertilizers as proximity to information, sources of input and credit supply and markets save time and reduce transportation costs Hassen et al. [43].

The study showed adoption of DAP fertilizer depends on location variables, farmer type, institutional factors and resource endowment. The study revealed that farmers residing in the SNNP cluster and Eastern and Western Oromiya apply significantly less DAP fertilizer to cereal crops as compared to farmers dwelling in Central Oromiya. On the contrary farmers in the Bahir Dar cluster apply significantly higher levels of DAP fertilizer as compared to farmers in central Oromiya. Model farmers are more likely to apply a higher amount of DAP fertilizer to cereal crops as compared to non-model farmers. Access to credit and cooperatives membership were the two institutional factors that were found to positively influence the level of DAP fertilized applied to cereal crops. The tropical livestock units and annual gross income significantly affected the adoption decision and level of DAP Tewodros et al. [44].

The study results showed that the decisions to use fertilizer and manure are negatively related to one another. Fertilizer is expensive in prices and inadequate in supply but less demanding of labour in its application. The parcel size has a positive effect on both land management practices. Access to credit is found to be significant in positively affecting the probability of using fertilizer. This implies that credit is very helpful in relieving capital constraints faced by farmers for using fertilizer and other purchased inputs Ketema and Siegfried [45].The use and intensity of adoption of fertilizer defined as function of age of the farmer, farmers' expectations of rainfall conditions and farmers' perception of the price of fertilizer Fufa and Hassan [46].

\section{Meta-analysis research questions for food Crop technology adoption}

i. What were the major food crop technologies had been transferred in agricultural sector in Ethiopia.

ii. Do differences exist in relation to proportion of technology adoption probability across study periods, data type used, region, model employed, and sample size used.

iii. Which small scale farmer socio-economic, institutional and demographic factors that significantly influences mean size effect of probability of food crop technology adoption.

\section{Results and Discussion}

The estimated LR 159 is highly statistically significant, its $\mathrm{p}$ value being practically zero. This points out that the model we have chosen gives a good fit. This suggests that the model we have chosen gives a good fit, although not every slope coefficient is statistically significant. This also justified that the regressors have strong influence on the choice probability (Table 1). 
Table 1: Model Fitting Information.

\begin{tabular}{|c|c|c|c|c|}
\hline \multicolumn{5}{|c|}{ Model Fitting Information } \\
\hline Model & $\begin{array}{c}-2 \text { Log } \\
\text { Likelihood }\end{array}$ & Chi-Square & Df & Sig. \\
\hline Intercept Only & 246.888 & & & \\
\hline Final & 159.006 & 87.881 & 6 & 0 \\
\hline Link function: Logit & & & & \\
\hline
\end{tabular}

The table above confirmed that the independent variables included in the model significantly affected the dependent variable. Hence, it recommended for further analysis and interpretation of results based on results estimated. The mode fitness also checked and confirmed by estimates Pseudo R-Square. From the estimates indicated by Negelkerke calculated value that the included explanatory variable explained $60 \%$ of Model estimate (Table 2).

Table 2: Pseudo R-Square.

\begin{tabular}{|c|c|}
\hline \multicolumn{2}{|c|}{ Pseudo R-Square } \\
\hline Cox and Snell & 0.534 \\
\hline Nagelkerke & 0.603 \\
\hline McFadden & 0.351 \\
\hline \multicolumn{2}{|c|}{ Link function: Logit } \\
\hline
\end{tabular}

As it indicated in the table above majority of the papers reviewed used Probit model (44.3\%) from which $12.17 \%$ articled used double hurdle probit, 6.09\% used multivariate Probit and 26.09\% used Probit. The proportion of critically reviewed papers that used Logit models was $20 \%$, Tobit model was $31.30 \%$ and $4.35 \%$ used two limit Tobit model. This summarized table indicated that $55.7 \%$ of reviewed articles used Tobit and Logit models (Table 3\&4).

Table 3: Test of Parallel Lines ${ }^{a}$.

\begin{tabular}{|c|c|c|c|c|}
\hline Model & $\begin{array}{c}-2 \text { Log } \\
\text { Likelihood }\end{array}$ & Chi-Square & df & Sig. \\
\hline $\begin{array}{c}\text { Null } \\
\text { Hypothesis }\end{array}$ & 159.006 & & & \\
\hline General & $.000^{\mathrm{b}}$ & 159.006 & 6 & 0 \\
\hline \multicolumn{3}{|c|}{$\begin{array}{c}\text { The null hypothesis states that the location parameters (slope } \\
\text { coefficients) are the same across response categories. }\end{array}$} \\
\hline $\begin{array}{l}\text { a. Link function: Logit. b. The log-likelihood value is practically zero. } \\
\text { There may be a complete separation in the data. The maximum } \\
\text { likelihood estimates do not exist }\end{array}$ \\
\hline
\end{tabular}

Table 4: Model Used defined as 1 if Probit.

\begin{tabular}{|c|c|c|c|c|}
\hline $\begin{array}{c}\text { Model } \\
\text { category }\end{array}$ & Frequency & Percent & $\begin{array}{c}\text { Valid } \\
\text { Percent }\end{array}$ & $\begin{array}{c}\text { Cumulative } \\
\text { Percent }\end{array}$ \\
\hline $\begin{array}{c}\text { Other } \\
\text { models }\end{array}$ & 64 & 55.65 & 55.65 & 55.65 \\
\hline Probit & 51 & 44.45 & 44.3 & 100 \\
\hline Total & 115 & 100 & 100 & \\
\hline
\end{tabular}

The table above indicated that the articles reviewed carried out unequally over the regions of the country that justified by finding $64.35 \%$ papers studied in Oromiya Region. In relation to production potentiality, existence of numerous learning and research institute, market proximity provoked the probability of the study to be carried out at single region (Table 5).
Table 5: Region where food crop adoption study carried out.

\begin{tabular}{|c|c|c|c|}
\hline Study region & Frequency & Percent & Cumulative Percent \\
\hline Amhara & 18 & 15.65 & 15.65 \\
\hline Oromiya & 74 & 64.35 & 80 \\
\hline SNNPR & 21 & 18.26 & 98.26 \\
\hline Tigray & 2 & 1.74 & 100 \\
\hline Total & 115 & 100 & \\
\hline
\end{tabular}

The table above showed that it was improved food crop varieties that majorly known as improved food crop technologies that thoroughly adopted and widely used in major food crop producers in the country. The result indicated that for sustainable dissemination and utilization of agricultural technologies, it demands integrated crop technology approach that entail combination of variety, fertilizer and other agronomic practices. The descriptive analysis summarized in the table above showed that the adoption of improved food crop varieties holds the lion share (71\%) of total adoption of the farmers. The result implied that the known agricultural technologies usually used was improved food crop varieties and the remaining less than one third of farmers categorized by using the technologies such as artificial fertilizer, chemicals and sowing methods (Table 6).

Table 6: Food Crop technology type defined and adopted.

\begin{tabular}{|c|c|c|c|}
\hline $\begin{array}{c}\text { Crop technology } \\
\text { types }\end{array}$ & Frequency & Percent & Cumulative Percent \\
\hline Improved varieties & 82 & 71.3 & 71.3 \\
\hline Artificial fertilizer & 14 & 12.17 & 83.48 \\
\hline Chemicals & 4 & 3.48 & 86.96 \\
\hline Sowing method & 15 & 13.05 & 100 \\
\hline Total & 115 & 100 & \\
\hline
\end{tabular}

The proportion of farmers belongs to lower adoption rate of crop technologies took the leading position (33\%) in proportion and that belongs to moderate adoption rate follows and finally the higher adoption rated farmers. The proportion of farmers categorized under moderate and higher adoption rate summed to be $67 \%$ (Table $7 \& 8$ ).

Table 7: Categories of food crop Adoption rate.

\begin{tabular}{|c|c|c|c|}
\hline Adoption rate & Frequency & Percent & Cumulative Percent \\
\hline High adoption & 33 & 28.4 & 28.4 \\
\hline Moderate adoption & 45 & 38.8 & 67.2 \\
\hline Low adoption & 38 & 32.8 & 100 \\
\hline Total & 116 & 100 & \\
\hline Total & 115 & 100 & \\
\hline
\end{tabular}

Table 8: Factors affecting Mean size effect of food crop technology adoptions in Ethiopia.

\begin{tabular}{|c|c|c|c|c|}
\hline Variables & $\begin{array}{c}\text { Mean Size } \\
\text { Effect }\end{array}$ & $\begin{array}{c}\text { Odds } \\
\text { Ratio }\end{array}$ & $\begin{array}{c}\text { Standard } \\
\text { Error }\end{array}$ & t values \\
\hline Age & 0.002 & 1 & 0.003 & 0.632 \\
\hline Training & 0.28 & 1.32 & 0.08 & $3.69^{* * *}$ \\
\hline Family size & 0.2 & 1.23 & 2.21 & 0.09 \\
\hline Farm size & 0.14 & 1.15 & 0.03 & $4.20^{* * *}$ \\
\hline Extension contact & 0.151 & 1.16 & 0.05 & $3.033^{* * *}$ \\
\hline
\end{tabular}




\begin{tabular}{|c|c|c|c|c|}
\hline Market distance & -0.312 & 0.73 & 0.005 & $58.386^{* * *}$ \\
\hline Credit access & 0.84 & 2.32 & 0.26 & $3.231^{* * *}$ \\
\hline TLU & 0.002 & 1 & 0.014 & 0.12 \\
\hline Income & 0.0002 & 1 & 0.000053 & $4.27^{* * *}$ \\
\hline Oxen Holding & 0.14 & 1.15 & 0.04 & $3.67^{* * *}$ \\
\hline Irrigation access & 0.313 & 1.37 & 0.076 & $4.16^{* * *}$ \\
\hline District & -0.278 & 0.76 & 0.061 & $4.553^{* * *}$ \\
\hline Gender & -0.637 & 0.53 & 0.397 & -1.605 \\
\hline Road access & 6.342 & 567.92 & 3.799 & 1.669 \\
\hline $\begin{array}{c}\text { Cooperative } \\
\text { membership }\end{array}$ & 0.458 & 1.58 & 0.143 & $3.209^{* * *}$ \\
\hline Fertilizer level & 0.773 & 2.17 & 0.227 & $3.401^{* * *}$ \\
\hline
\end{tabular}

The variables are highly significant at $1 \%$ (***) $^{*}$ significant level

In Meta-analysis sixteen explanatory variables were used and out of which eleven significantly affected the Mean size effect of the technology adoption. The regression analysis justified that mean size effect of food crop technology adoption depends on training and credit access, farm size, extension contact, market distance, income earned from off-farm and farm, oxen holding, irrigation access, district potentiality, road access ,cooperative membership, fertilizer level used,. From these explanatory variables used, market distance is negatively related with mean size effect on adoption rate of food crop technology.

Training access: The parameter estimate was 0.28 that showed, holding other variables constant; having one unit of training provokes the likelihood of technology adoption by $32 \%$. The Meta-analysis result confirmed that through improving training access for food crop technologies, it is possible to enhance technology adoption. The Meta-analysis result also in line with Tesfaye et al. that reported as Participation on field day is one of the means of teaching and learning process of improved technologies, it promoted technology dissemination through demonstration.

Farm size: The parameter estimates of the variable farm size estimated to be 0.2 that indicated increase farm size by one unit, increase the likelihood of adoption of food crop by 0.2 units, others variable fixed constant. The small-scale farmer that acquainted with one more ha possessed more of 15\% higher likelihood to adopt food crop technology adoptions, holding other variables constant. This implies, since they can handover risks of the technology failure and success through diversification the small-scale farmers acquainted with larger farm size higher in adoption probability of food crop technology. The finding is in line with Dawit et al, that reported adoption of improved highland maize varieties by farmers is influenced by farm size. Gumataw et al. also supported the study by summarizing the report as land owned provokes improved potato farming.

Market distance: The parameter estimate referred distance from farmers' residence up to market point found to be -0.312 . This showed that one if the farmers away from market point by $1 \mathrm{~km}$ unit in comparison to other farmer, the adoption probability of the farmer increase by proportion of 73\%, holding other variables constant. The result points out that through improving access to market points, there is the probability of technology adoption for food crops in the country. The study results also supported by Bedru et al, where the finding reported as market distance inversely related and influenced by distance.

Credit access: The Meta-analysis result indicated that credit access is one of important explanatory variables that significantly affect food crop technology adoption in the country. The calculated value of credit access was 2.32 implied that if the farmer able to access one more training in the improved practices of the technology, the likelihood of increment in adoption rate was by $32 \%$.This is also in line with Hessen et al. [47] that reported credit supply supports intensity and probability of the adoption of inorganic fertilizers.

Income earned: The parameter estimates of income earned from agricultural and nonagricultural activities found to be 0 . 0002.This indicated that enabling the small-scale farmers to get additional income support to adopt the farmer to adopt more likely. This is in in line with Dawit and Abduselam where the model result revealed that household income positively and significantly influenced the adoption and intensity of use of improved highland maize varieties.

Oxen holding: The parameter estimate referred oxen holding estimated to be 0.14 . This Meta-analysis result indicated that the small-scale farmers that owned one more additional ox, increase the adoption likelihood by more of $15 \%$ proportion, holding other variables constant. As one of major draft power for crop farming, enabling the farmer to have more ox make to adopt in better probability. This also supported by Chilot et al. that reported ownership of oxen positively affected with the likelihood and intensity of using improved varieties and inorganic fertilizer.

Irrigation access: The parameter estimates and its odds ratio for irrigation variable estimated to be 0.315 and 1.37 . The analyzed output indicated that the likelihood increasing access to irrigation promotes food crop technology adoption. Holding other variables constant, accessing farmers one more irrigation access increases the adoption probability by $37 \%$.

Study district: The parameter estimates and odds ratio for district variable calculated to be -0.28 and 0.76 . This implied that if the farmers forced to plant the food crops technology away from potential distinct, its likelihood of technology adoption decrease, holding other variables constant.

Cooperative membership: The parameter estimates for the variable cooperative membership for the farmers estimated to be 0.458 .This indicated that enabling farmers to be cooperative membership by one unit accelerate the technology adoption of food crops by $58 \%$, ceterisparibus.

Fertilizer level: The parameter estimates for the variable extent of fertilizer used calculated to be 0.77 . This justified that increase the extent of level adopted by more of one unit, increase the level of food crop technology adoption by $17 \%$, holding other variables constant (Table 9). As it is indicated in the table above, in 
the regression analysis, the estimate of both higher and moderate adoption rate probability used as dependant variable and study period, region, model type used, sample size, food crop technology type and data type used as independent variable. The dependant variable adoption defined as higher (for adoption above 65\%), moderate adoption rate (for adoption rate between $65 \%$ and $40 \%$ ) and low adoption rate (for adoption rate below 40\%). In the data analyzing estimating procedure the model used was Ordered logit Model. From these regressed explanatory variables under moderate adoption rate, food crop technology type, sample size and study period found to affect significantly affect the probably estimate, using low adoption rate as benchmark.

Table 9: Regression result for Ordered Logit model for food crop technology adoption.

\begin{tabular}{|c|c|c|c|c|c|c|c|c|c|}
\hline \multirow{2}{*}{\multicolumn{2}{|c|}{ Parameter estimates }} & \multirow{3}{*}{$\begin{array}{c}\text { Estimate } \\
1.51\end{array}$} & \multirow{3}{*}{$\begin{array}{c}\text { Std. Error } \\
1.276\end{array}$} & \multirow{3}{*}{$\begin{array}{c}\text { Wald } \\
1.4\end{array}$} & \multirow{3}{*}{$\begin{array}{l}\text { Df } \\
1\end{array}$} & \multirow{3}{*}{$\begin{array}{l}\text { Sig. } \\
0.237\end{array}$} & \multirow{3}{*}{$\begin{array}{c}\text { Odds ratio } \\
4.53\end{array}$} & \multicolumn{2}{|c|}{$95 \%$ conf. interval } \\
\hline & & & & & & & & \multirow{2}{*}{$\begin{array}{c}\text { Lower bound } \\
-0.991\end{array}$} & \multirow{2}{*}{$\begin{array}{c}\text { Upper bounc } \\
4.01\end{array}$} \\
\hline Thmold & $\begin{array}{l}\text { Adoption defined } 1 \text { if } \\
\text { higher adoption rate }\end{array}$ & & & & & & & & \\
\hline 111resnota & $\begin{array}{c}\text { Adoption rate defined } 2 \text { if } \\
\text { moderate }\end{array}$ & 4.608 & 1.407 & 10.72 & 1 & 0.001 & $100.28^{* * *}$ & 1.85 & 7.366 \\
\hline \multirow{11}{*}{ Location } & Sample size & 0.014 & 0.003 & 24.85 & 1 & 0 & 1.01 & 0.008 & 0.019 \\
\hline & \multirow{2}{*}{$\begin{array}{l}\text { Technology type defined } 1 \\
\text { if variety }\end{array}$} & 1.125 & 0.577 & 3.79 & 1 & 0.051 & $3.08^{*}$ & -0.007 & 2.257 \\
\hline & & $0^{\mathrm{a}}$ & . & . & 0 & . & & . & . \\
\hline & \multirow{2}{*}{ Model used 1ifprobit } & -0.431 & 0.478 & 0.81 & 1 & 0.367 & 0.65 & -1.367 & 0.506 \\
\hline & & $0^{\mathrm{a}}$ & . & . & 0 & . & & . & . \\
\hline & \multirow{2}{*}{$\begin{array}{l}\text { Region defined as } 1 \text { if } \\
\text { Oromiya }\end{array}$} & 0.916 & 0.567 & 2.62 & 1 & 0.106 & 2.49 & -0.194 & 2.027 \\
\hline & & $0^{\mathrm{a}}$ & . & . & 0 & . & & . & . \\
\hline & \multirow{2}{*}{$\begin{array}{l}\text { Study period defined } 1 \text { if } \\
\text { done after } 2010 \mathrm{ec}\end{array}$} & -2.09 & 0.77 & 7.37 & 1 & 0.007 & $0.12^{* * *}$ & -3.599 & -0.581 \\
\hline & & $0^{\mathrm{a}}$ &. & . & 0 & . & & . & . \\
\hline & \multirow{2}{*}{$\begin{array}{l}\text { Data type defined } 1 \text { if } \\
\text { cross-sectional }\end{array}$} & 0.035 & 0.978 & 0.001 & 1 & 0.972 & 1.04 & -1.881 & 1.951 \\
\hline & & $0^{\mathrm{a}}$ & . & . & 0 & . & & . & . \\
\hline & Link & nction: lo & A. This pa & eter is & zero & se it is & lundant. & & \\
\hline
\end{tabular}

The significance level of the explanatory variable explained as $1 \%\left(^{* * *}\right), 10 \%{ }^{* * *}$ level.

Food technology type: The regression coefficient and its odds ratio for technology type was 1.12 and 3.08. it indicated that if we increase the access of technologies other than improved variety by a unit, the ordered log-odds of being in a moderate adoption category increases by about 1.12, holding all other regressors constant. It can be also reported that if the farmers accessed more one technology other than improved varieties, the likelihood of farmers to be under moderate adoption category increase by $8 \%$, holding other variables constant. In comparison to low adoption rate, under moderate adoption probability estimate increase as the farmers moved away from improved varieties technologies to other types (fertilizer, chemical and seeding rate), holding other variables fixed. This implies that different food crop technology owned different among small scale farmers. This is in contrary to other review by Chilot and Dawit [48] finding that indicated almost all of the crop technology adoption studies concerned on improved seeds and chemical fertilizers. For the sustainable productivity improvement and the accelerated technology transfer, it is indispensable not only to use improved variety only or together with fertilizer, rather full package approach.

Sample size: The parameter estimates and odds ratio for variable sample size estimated to be 0.014 and 1.01 . The regressions also confirmed the existence of direct relation between Sample size and probability estimate for food technology adopted. By using low adoption rate as reference point, the reviewed results implied that as sample size increase moderate the adoption estimate increase.
This implied that when the sample size increase by unit, the percentage increment in food crop technology adoption was by $1 \%$, holding other variables fixed. The Meta-analysis result pointed out that the higher or lower probability estimate of food technology adoption could not be the real estimate of the study, rather due to data management problem and consequently could increase with increased sample size.

Study period: The parameter estimates, and its respective odds ratio was calculated -2.09 and 0.12 . The ordered Logit model also justified existence of inverse relation between moderate adoption probability estimate and study period, holding other variables constant. This implied that the when the study period approached to this period by one unit, probability estimate of food technology decrease by $12 \%$, at ceteriusparibus condition. In the relation frequent appearance of climate variability and risk aversion behavior of farmer, the adoption probability seemed falling and calls for shift rain fed agriculture system to irrigationbased farming.

\section{Conclusion}

The Meta-analysis studies aimed to summarize the detrimental factors of food crop technology adoption at country level through critical review and analysis. The study targeted to provide information for technology adoption factors that not well identified and organized in the manner which can be suited for policy formulation and implementation. Hence the Meta-analysis 
focused to identify factors affecting estimate of probability of food crop adoption and the mean size effect certain socioeconomic, institutional and demographic factors probability adoption. The mean size effect of socioeconomic, institutional and demographic factors manipulated using Excel sheet from coefficient value of independent and standard error estimate. The estimating weighted mean size value calculated from variance, standard error and its significance checked by t-value for each explanatory variable estimate.

The Ordered Logit model was used for estimating probability of food crop technology. In the analysis 150 explanatory variables collected and merged to 48 observations from 48 case studies done in the country. The result also implied that the attention given for different food crop technologies at country level was uneven and these was one f probable reason for low adoption of the technology due to difference in value across small scale farmers and other stakeholders. This implies that the technology development and dissemination system focused on only few types and lacks integrated technology transfer approach. The result from Meta-analysis indicated that factors affecting moderate estimate of probability of food crop technology adoption is function of sample size, technology type and study period. The mean size effect analysis indicated that food crop technology adoption depends on access to training, irrigation and credit, tropical livestock unit, fertilizer level, district potentiality, cooperative membership, oxen holding, extension contact and market distance. The analyzed output clarified the existence of excellent opportunity for supporting and accelerating dissemination of food crop technology through capacity building, improving institutional linkage and service provision, irrigation and livestock holding and adoption of integrated full packaged of food crop technologies.

The result also indicated that the estimate of food crop adoption probability was known to be positive function of sample size and technology type and inversely related to the study period. The analysis results implied that appropriate model selection, sample size determined, study period for specific technology known to play influential function on the probability estimate of food crop technology adoption.

\section{Acknowledgement}

None.

\section{Conflict of Interest}

No Conflict of Interest.

\section{References}

1. Abdul Rehman, Luan Jing dong, Rafia Khatoon, Imran Hussain (2016) Modern Agricultural Technology Adoption its Importance, Role and Usage for the Improvement of Agriculture. Luan Jingdong, College of Economics and Management, Anhui Agricultural University, China. University of Azad Jammu and Kashmir Undergraduate Student, Allama Iqbal Open University, Pakistan. American-Eurasian J Agric \& Environ Sci 16(2): 284-288.

2. Paul E Waggoner (2004) Agricultural technology and its societal implications. The Connecticut Agricultural Experiment Station, Box 1106, New Haven, CT 06504-1106, USA.
3. Nizam Husen A, Tim Loos K, Khalid Siddig H A (2017) Social Capital and Agricultural Technology Adoption among Ethiopian Farmers. International Livestock Research Institute (ILRI), Addis Ababa Ethiopia, University of Hohenheim, Stuttgart, Germany, Humboldt University of Berlin, Germany and Khartoum University, the Sudan. American Journal of Rural Development, 5, No. 3, 65-72, Science and Education publicising.

4. Berihun Kassa, Bihon Kassa, Kibrom Aregawi (2014) Adoption and Impact of Agricultural Technologies on Farm Income: Evidence from Southern Tigray, Northern Ethiopia, College of Social Science and Humanities, Samara University, P.O. Box 132, Samara, College of Business and Economics, Mekelle University, Ethiopia. International Journal of Food and Agricultural Economics 2(4): 91-106.

5. Tigabu D G, Gebeyehu M F (2018) Agricultural Extension Service and Technology Adoption for Food and Nutrition Security: Evidence from Ethiopia. FARA Research Report 3(4): 30.

6. Leggesse Dadi, Michael Burton, Adam Ozanne, Hagos Kidane Mezgebo, Girma Tesfahun (2018) Duration Analysis of Technological Adoption in Ethiopian Agriculture. Journal of Agricultural Economics 55(3): 613631.

7. Melesse B (2018) A Review on Factors Affecting Adoption of Agricultural New Technologies in Ethiopia. J Agri Sci Food Res 9: 226.

8. Aynalem Shita, Nand Kumar, Seema Singh (2018) Agricultural Technology Adoption and Its Determinants in Ethiopia: A Reviewed Paper. Asia Pacific Journal of Research I 2347-4793.

9. Admassie and Gezahegn Ayele (2009) Adoption of Improved Technology in Ethiopia. Ethiopian Journal of Economics19(1). Addis Ababa, Ethiopia.

10. Solomon Asfaw, Bekele Shiferaw, Franklin Simtowe, Messia Hagos (2011) Agricultural technology adoption, seed access constraints and commercialization in Ethiopia. Food and Agricultural Organization of the United Nations, Agricultural Development Economics Division, Rome, Italy. International Maize and Wheat Improvement Centre, UN Avenue, Gigiri, Nairobi, Kenya. International Crops Research Institute for the Semi-Arid Tropics, UN Avenue, Gigiri, Nairobi, Kenya. Ethiopian Economics Association, Addis Ababa, Ethiopia. Journal of Development and Agricultural Economics 3(9): 436-447

11. Chilot Yirga, Takale Mebratu, Ali Mohammad, Shiferaw, Hugo de Groote, et al. (2013) Analysis of adoption and diffusion of improved wheat technologies in Ethiopia, International Wheat and Maize Research Institute, Nairobi, Kenya. Institute of Agricultural Research and International Wheat and Maize Research Institute (CIMMYT), Addis Ababa, Ethiopia.

12. Doss C R, Mwangi W, Verkuijl H, H de Groote (2003) Adoption of Maize and Wheat Technologies in Eastern Africa: A Synthesis of the Findings of 22 Case Studies. CIMMYT Economics Working Paper 03-06. D F: CIMMYT, Mexico.

13. Yohannes Kebede, Kisan Gunjal, Garth Coffin (1990) Adoption of New Technologies in Ethiopian Agriculture: The Case of Tegulet-Bulga District, Shoa Province 27 Department of Agricultural Economics, McGill University, Ste Anne de Bellevue, Que, H9X 1CO Canada.

14. Bingxin Yu, Alejandro Nin Pratt, José Funes Sinafikeh, Asrat Gemessa (2011) Cereal Production and Technology Adoption in Ethiopia, International Food Policy Research Institute Discussion Paper 01131, Ethiopia Strategy Support Program II ESSP II Working Paper 31, Development Strategy and Governance Division, Addis Ababa, Ethiopia.

15. Bingxin Yu, Alejandro Nin Pratt (2014) Fertilizer Adoption in Ethiopia Cereal production. Acadamic Journal of development and Agricultural Economics 6(7): 318-337.

16. Chilot Yirga, Yigezu Atnafe, Aden Aw Hassan (2015) A Multivariate Analysis of Factors Affecting Adoption of Improved Varieties of Multiple Crops: A Case Study from Ethiopian Highlands 1Ethiopian Institute of Agricultural Research (EIAR), Addis Ababa, Ethioia. International Center for Agricultural Research in the Dry Areas (ICARDA), Amman, Jordan Ethiop J Agric Sci 25(2): 29-45.

17. Mideksa Bekele, Tadele Shiberu (2014) Adoption of Improved Bread Wheat Varieties on Small-Scale Farmers: The Case of Boji Gebisa Ambo District, Oromia Regional State, Ethiopia. American Journal of Food Science and Technology 2(3): 103-108. 
18. Tesfaye Solomon, Ayele Tessema, Adam Bekele (2014) Adoption of improved wheat varieties in Robe and Digelu Tijo Districts of Arsi Zone in Oromia Region, Ethiopia: A double-hurdle approach.Kulumsa Agricultural Research Center, Assela, Ethiopia,School of Environment, Gender and Development Studies, College Of Agriculture, Hawassa University, Ethiopia, Melkasa Agricultural Research Center, Melkasa, Ethiopia. African Journal of Agricultural Research 9(51): 3692-3703.

19. Bekele Hundie Kotu, Hugo Verkuij, Wilfred Mwangi, Douglas Tanne (2000) Adoption of Improved Wheat Technologies in Adaba and Dodola Woredas of the Bale Highlands, Ethiopia.Sinana Agricultural Research Centre, Bale, Ethiopia and International Maize and Wheat Improvement Center, Addis Ababa, Ethiopia.

20. Geremew Kefyalew, Abdi Bedilu, Muzeyin Ahmed, Workineh Mena (2016) Analysis of Smallholder Farmer's Adoption and continued application of Teff Row Planting Analysis of Smallholder Farmer's Adoption and Continued Application of Teff Row Planting Techniquaes inWolaita Zone. Wolaita Sodo University, College of Business an Ethiopia and, College of Natural and Computational Sciences, Wolaita, Ethiopia.

21. Tafese T (2016) Adoption and Intensity of Row Seeding: Case of Wolaita Zone. Open Access Library Journal 3: e2443.

22. Joachim Vandercasteelen, Mekdim Dereje, Bart Minten, Alemayehu Seyoum Taffesse (2013) Scaling-up adoption of improved technologies: The impact of the promotion of row planting on farmers' Teff yields in Ethiopia. Discussion Paper 344. Faculty of Economics and Business. LICOS Centre for Institutions and Economic Performance Waaistraat, Leuven, Belgium.

23. Dawit Milkias, Abduselam Abdulahi (2018) Factors Influencing Intensity of Adoption of Improved Highland Maize Varieties: The Case of Toke Kutaye District, West Shewa Zone, Oromia Regional State, Ethiopia. Ambo Agricultural Research Center, Ethiopian Institute of Agricultural Research/EIAR/, Ambo, Ethiopia Department of Agricultural Economics, Kebri Dehar University, Kebridehar, Ethiopia. Journal of Investment and Management 7(4): 125-132.

24. Ketema M, Kebede D (2017) Adoption Intensity of Inorganic Fertilizers in Maize Production: Empirical Evidence from Smallholder Farmers in Eastern Ethiopia. School of Agricultural Economics and Agribusiness, Haramaya University, Haramaya, Ethiopia Correspondence: Mengistu Ketema, School of Agricultural Economics and Agribusiness, Haramaya University, P.O. Box 48, Haramaya, Ethiopia. Journal of Agricultural Science 9(5).

25. Musa Hasen (2015) Adoption of multiple agricultural technologies in maize production of the Central Rift Valley of Ethiopia. Haramaya University, P O Box 95, Dire Dawa, Ethiopia. Studies in Agricultural Economics 117 (2015) 162-168. American Journal of Rural Development 5(3): 65-72.

26. Bedru Beshir, Dagne Wegray (2014) Determinants of small holder's hybrid maize varieties adoption in drought prone central Rift Valley of Ethiopia. African Journal of Agricultural Research 9(17): 1334-1343.

27. Bedru Beshir, Koichi Usami, Yoshiaki Nishikawa (2013) Determinants of Adoption of Improved Open Pollinated Varieties of Maize in Drought Prone Areas of Central Ethiopia, Graduate School of International Development, Graduate School of International Development, Nagoya University, Japan.

28. Abadi Teferi, Damas Philip, Moti Jaleta (2015) Factors that affect the adoption of improved maize varieties by smallholder farmers in Central Oromiya, Ethiopia. Developing Country Studies ISTE 2224-607X (Online) 5(15)

29. Kebede D, Ketema M (2017) Why do Smallholder Farmers Apply Inorganic Fertilizers below the Recommended Rates? Empirical Evidence from Potato Production in Eastern Ethiopia. Adv Crop Sci Tech 5: 265 .

30. Tesfaye Zegeye, Alemu Haileye (2003) Adoption of Improved Maize Technologies and Inorganic Fertilizer in North-western Ethiopia Research Report No. 40. Ethiopian Agricultural Research organization. Addis Ababa, Ethiopia.

31. Musba Kedir (2018) Adoption and determinants of improved maize in Ethiopia. Ethiopian Institute of Agricultural Research, Asossa Agricultral Research Center,Asosa, Ethiopia. Agricultural Journal 13(1): 1-8.
32. Kinfe H (2018) Yield performance and adoption of released sorghum varieties in Ethiopia. Edelweiss Applied Science Tech 2: 46-55.

33. Gumataw K Abebe, Jos Bijman, Stefano Pascucci, Onno Omta (2013) Adoption of improved potato varieties in Ethiopia: The role of agricultural knowledge and innovation system and smallholder farmers' quality assessment a Wageningen University, Management Studies, Hollandseweg, 6706 KN Wageningen, The Netherlands, b Hawassa University, P.O. Box 05, Hawassa, Ethiopia. 2013 Elsevier Ltd. Agricultural Systems 122(2013): 22-32.

34. Ketema Mengistu, Kebede Degefu, Dechassa Nigussie, Hundessa Feyisa (2016) Determinants of Adoption of Potato Production Technology Package by Smallholder Farmers: Evidences from Eastern Ethiopia. School of Agricultural Economics and Agribusiness, Haramaya University, Ethiopia, School of Plant Sciences, Haramaya University, Ethiopia. School of Animal and Range Sciences, Haramaya University, Ethiopia. Review of Agricultural and Applied Economics.

35. Alemneh Kabata, Carol Henry, Debebe Moges, Afework Kebebu, Susan Whiting, et al. (2016) Determinants and Constraints of Pulse Production and Consumption among Farming Households of Ethiopia. Journal of Food Research 6(1), Published by Canadian Center of Science and Education, Canada.

36. Hagos Kidane, Mezgebo, Girma Tesfahun (2018) Determinants of the adoption of improved faba bean varieties in Enda-Mehoni district, South Tigray, Northern Ethiopia.Tigray Agricultural Research Institute, Alamata Agricultural Research Center, Alamata, Ethiopia. International Livestock Research Institute, International Center for Agricultural Research in Dry land Areas, Addis Ababa, Ethiopia. Journal of Development and Agricultural Economics 10(10): 352-358

37. Solomon Asfaw, Bekele Shiferaw, Franklin Simtowe (2010) Does Technology Adoption Promote Commercialization? Evidence from Chickpea Technologies in Ethiopia. International Maize and Wheat Improvement Centre (CIMMYT), UN Avenue, Kenya.

38. Daniel Masresha, Belaineh Legesse, Jema Haji, Lemma Zemedu (2017) Determinants of the adoption of improved white haricot beans in East Shewa Zone, South-Eastern Ethiopia.School of Agricultural Economics and Agribusiness, Haramaya University, Haramaya University, Ethiopia. Journal of developmet and Agricultral Economics 9(12): 355-37.

39. Yitayal Abebe, Adam Bekele (2015) Analysis of adoption spell of improved common bean varieties in the central rift valley of Ethiopia: A duration model approach. Ethiopian Institute of Agricultural Research, Melkasa Agricultural Research Center, Adama, Ethiopia. Journal of Agricultural Economics and Development 4(3): 037-043.

40. Amanuel A, Girma A (2018) Production Status, Adoption of Improved Common Bean (Phaseolus vulgaris L.) Varieties and Associated Agronomic Practices in Ethiopia. J Plant Sci Res 5(1): 178.

41. Earo and ICRSAT (2003) Ethiopian Agricultural Research Organization PO Box 2003, Addis Ababa, Ethiopia and International Crops Research Institute for the Semi-Arid Tropics Patancheru 502 324, Andhra Pradesh, India. Adoption Studies on Improved Chickpea Varieties in Ethiopia.

42. Samuel Diro, Efrem Asfaw, Beza Erko, Misganaw Anteneh (2017) Factors affecting adoption and degree of adoption of soybean in Ilu-Ababora Zone; South western Ethiopia. Agricultural economics research process, Agricultural extension and gender research process, Jimma Agricultural research centre, Jimma, Ethiopia. Agricultural Science Research Journal $7(1): 15-26$

43. Gujarati Damodar (2012) Econometrics by Example. Palgrave Macmillan in the US is a division of St Martin's Press LLC, 175 Fifth Avenue, New York, USA.

44. Tewodros Tefera, Girmay Tesfay, Eyasu Elias, Mulugeta Diro, Irene Koomen (2016) Drivers for adoption of agricultural technologies and practices in Ethiopia. A study report from 30 woredas in four regions. Hawssa University, Hawassa and Mekelle University, Mekele. Cascape Project, Wageningen University and Research Centre, CASCAPE, Addis Ababa/Wageningen, Ethiopia.

45. Ketema M, Siegfried Bauer (2011) Determinants of Manure and Fertilizer Applications in Eastern Highlands of Ethiopia. Haramaya University, Ethiopia and Justus Liebig University of Giessen, Germany. Quarterly Journal of International Agriculture: 237-252. 
46. Fufa B, Hassan RM (2006) Determinants of fertilizer use on maize in Eastern Ethiopia: A weighted endogenous sampling analysis of the extent and intensity of adoption. Agrekon 45(1).

47. Hassen Beshir, Bezabih Emana, Belay Kassa, Jema Haji (2012) Determinants of chemical fertilizer technology adoption in North eastern highlands of Ethiopia: the double hurdle approach. Wollo University, Department of Agricultural Economics, Ethiopia, SID Consult, Addis
Ababa, Ethiopia Haramaya University, School of Agricultural Economics and Agribusiness, Ethiopia.

48. Chilot Yirga, Dawit Alemu (2016) Adoption of crop technologies among smallholder farmers in Ethiopia. Ethiopian Institute of Agricultural Research, Addis Ababa, Ethiopia. EIAR 50th Year Jubilee Anniversary Special Issue: 1-16. 